1990) is to cell biology, providing a coherent and accurate description of the important areas and being one step removed from primary references (ideal for lecturers wishing to update their courses). The book has the conventional organization of many immunology courses, describing the antibody response, then the major histocompatibility complex, antigen presentation and $\mathrm{T}$-cell recognition, followed by the $\mathrm{T}$-cell response and lymphocyte ontogeny. The last section is a disease-oriented treatment of systemic immunology that does not lose sight of the molecular and cellular mechanisms.

For the $\mathrm{PhD}$ student, I recommend two textbooks, each having a very different approach. Most recently published is Immunology: A Synthesis by Golub and Green. Like Golub's previous textbooks, the book is a tribute to the history of immunology, describing the experiments that gave rise to currently accepted ideas. It is wonderful reading for those who want to know where the field has come from and the way in which immunological concepts have evolved. And for teaching purposes, the approach works well when dealing with immunochemistry, a subject that is often presented in a dull, factual fashion. But for cellular immunology it adds unnecessary complication to a field that has recently benefited from clarification at the molecular level. On the other hand, for those already familiar with the area, the discussions of the early experiments and unresolved issues, such as the nature of suppressor cells, are very useful.

The almost philosophical approach of Golub and Green is complementary to the didactic Fundamental Immunology by William Paul, published by Raven Press in 1989. This textbook, originating from the US National Institutes of Health, is a comprehensive collection of sophisticated review articles, less personally biased than those in Annual Reviews of Immunology, but pitched at the same level. Because each chapter is written by a different individual, the book lacks the coherence of Golub and Green's, providing instead thoughtful direction to the primary literature for both teachers and PhD students.

So we now have a choice of books in a variety of institutional styles, and should perhaps adapt our own syllabuses to encourage students to read these books. And if your favourite immunological style or philosophy has yet to be expressed in a textbook, you can rest assured that it will not be long until it is.

Frances $M$. Brodsky is in the Departments of Pharmacy and Pharmaceutical Chemistry, and of Microbiology and Immunology, University of California, San Francisco, California 94143-0446, USA.

\section{Combining forces}

\section{Marian Stamp Dawkins}

The Development and Integration of Behaviour: Essays in Honour of Robert Hinde. Edited by Patrick Bateson. Cambridge University Press: 1991. Pp. 506. $£ 50, \$ 95$ (hbk); £17.50, \$29.95 (pbk).

SOME scientists contribute to their field by showing up fallacious thinking and pointing out erroneous or ill-conceived assumptions. A few contribute by bringing together diverse fields of study, starting constructive new areas of research by a synthesis of different ideas. Fewer still manage to do both. Robert Hinde is one of them, and this collection of essays is a testament both to his breadth of vision and to the force of his intellect. The range of his interests is astonishing. The essays by Patrick Bateson on the processes underlying the development of behaviour, by Gabriel Horn on imprinting and by Peter Marler on the development of song in birds, all show the impact that he has had on ontogenetic studies of behaviour. Richard Andrew, in describing his own work on the effect of testosterone on behaviour, bluntly says that Hinde taught him about the causal basis of behaviour. John Fentress and J. B. Hutchison write substantial essays on hormonal and neural aspects of development, both with obvious debts to Hinde's work.

Then there is Hinde's work on social relationships. The essays on this by Thelma Rowell, Michael Simpson and Jay Rosenblatt show that here, too, his influence has been extraordinarily powerful. John Bowlby, Joan Stevenson-Hinde, Michael Rutter, Judt Dunn and Marian Radke-Yarrow all write on yet another of Hinde's interests, the development of human behaviour. Here, his ability to bring rigour and clarity to fields where there is often a danger of losing sight of these attributes is again apparent. And, as if this were not enough for one man's life, Hinde has had a considerable indirect influence on ethological fieldwork, even though he has never been directly involved in this himself. This influence is pointed out by Tim Clutton-Brock in an essay on the evolution of sex differences. By supervising the work of Jane Goodall on chimpanzees and numerous others studying primates in the wild, and insisting that data should be precise and quantitative, Hinde was responsible for lifting the quality of primate field studies so that they surpassed those on most other groups.

This is certainly not a book in which the contributors wrote what they wanted to and then later felt they ought to 'think of something nice to say about Robert'. Quite the contrary. The whole book gives the distinct impression that all the chapters were written by people genuinely and heavily indebted to Hinde and that they chose their words carefully because each knew that Hinde himself could (and probably would) pick them up on any loose thinking. As a festschrift it is unusual, partly because the person being honoured actually contributes to the volume himself and partly because the book is so forward-looking and contains up-to-date and useful reviews on a variety of subjects. The essays by Marler on bird song and Horn on imprinting are particularly valuable in this respect. And I shall certainly recommend human sciences undergraduates to read David Hamburg's chapter on aggression and war, inspired by yet another example of Hinde's unique ability to synthesize diverse fields while being ruthlessly rigorous. In this case Hinde applies ethology to the problem of the destructive tendencies of human beings.

The whole book is woven together by what is clearly a strong thread of affection from those who have worked with Hinde. The 'memoirs' at the end by Jane Goodall and Niko Tinbergen are the clearest examples of this but it is also patently obvious in all the other chapters, even when the authors are recalling moments when Hinde was pointing out some fallacy in their work.

Pat Bateson introduces the book, and skilfully forestalls the possible criticism that behavioural studies at Cambridge University under Hinde's guidance "never used a simple explanation when a more complicated one will do". He does this by first using the quotation himself and then going on to explain its more serious implications. Hinde's emphasis on the complexity of factors that affect behaviour is neither trivial nor a retreat from testable explanations. Instead, it is a genuine reflection of the fact that the phenomena studied by ethologists are complex and deserve to be seen as such.

Quite apart from being a fitting tribute to a man who has made important cor tributions to so many fields, this is a well-edited and well-chosen collection of essays. Many are extremely useful and topical reviews in their own right. Most scientists would, I suspect, be more than content if in the course of their careers they had inspired half as many people to do half as many different things as Hinde has demonstrably done.

Marian Stamp Dawkins is in the Animal Behaviour Research Group, Department of Zoology, South Parks Road, Oxford OX1 3PS, UK. 